\title{
Morfologia das domácias foliares de Miconia sellowiana Naudin (Melastomataceae)
}

\author{
Letícia Larcher de Carvalho \\ Maria Regina Boeger \\ Alline Flores de Brito \\ Renato Goldenberg \\ Departamento de Botânica, Setor de Ciências Biológicas \\ Caixa Postal 19031 \\ Universidade Federal do Paraná, Curitiba, PR, Brasil \\ CEP 81.531 .990 \\ *Autor para correspondência \\ rboeger@ufpr.br
}

Submetido em 14/03/2011

Aceito para publicação em 08/10/2011

\section{Resumo}

Domácias são cavidades encontradas na superfície foliar que proporcionam condições físicas para a existência de artrópodes, caracterizando uma relação mutualística. Apesar da importância ecológica das domácias, poucos estudos descrevem sua estrutura e relação com o ambiente. Miconia sellowiana apresenta domácias na face abaxial da folha e estudos prévios sobre essa espécie, oriundas de duas fitofisionomias, indicaram a influência dos fatores ambientais sobre a morfologia foliar. Assim, esse estudo analisou comparativamente a morfologia das domácias foliares de $M$. sellowiana e a influência dos fatores ambientais nestas estruturas. Folhas provenientes da Estepe-gramíneo-lenhosa e da Floresta Ombrófila Mista foram coletadas para a análise da espessura e a área das domácias, assim como a área, a massa seca e a espessura do limbo. As folhas de M. sellowiana apresentaram apenas um tipo de domácia, na face abaxial e basal da folha, com uma estrutura anatômica mais simples do que a lâmina foliar na qual estão localizadas, com ausência de estômatos e de mesofilo dorsiventral, sugerindo que a capacidade fotossintética das domácias é menor que a da lâmina foliar. A variação morfológica nas domácias entre as duas áreas/regiões ocorreu apenas no tamanho, representado pela maior área nas folhas da Estepe Gramíneo Lenhosa, indicando a influência dos fatores ambientais na seleção dos ácaros hospedeiros.

Palavras-chave: Ácaros, Anatomia de domácias, Melastomataceae

\section{Abstract}

Leaf domatia morphology of Miconia sellowiana Naudin (Melastomataceae). Domatia are small cavities that shelter and provide an adequate physical microenvironment for arthropods, and are often found on leaves. Besides their ecological importance, few studies have described the structure of domatia. Miconia sellowiana has domatia on the abaxial surface of its leaves, and previous studies indicate that environmental factors influence the leaf morphology of this species. The goal of this study was to analyze the domatia morphology of M. sellowiana and to describe the environmental factors that possibly influence these structures. Leaves from two different vegetation types, grassland and Araucaria forest, were collected. Domatia thickness, area and dry weight, and 
leaf thickness were analyzed. The leaves have only one type of domatium, located on the abaxial surface of the leaf base. The anatomical structure of the domatia is less complex than the leaf blade, with a homogeneous mesophyll and without stomata. These features suggest that the photosynthetic capacity of the domatia is lower than the remaining part of the leaf blade. The only morphological variation of the domatia from the two areas was in size, with larger domatia in the grassland leaves. This might indicate the influence of environmental factors on the selection of host mites.

Key words: Anatomy of domatia, Melastomataceae, Mites

\section{Introdução}

As domácias são pequenas cavidades que ocorrem geralmente na facial abaxial das folhas, encerrando espaços diminutos na junção das maiores veias (WILKINSON, 1979; O’DOWD; WILLSON, 1989). Apresentam forma variada entre as espécies e entre indivíduos da mesma espécie, o que sugere que seu significado adaptativo difere de acordo com a sua morfologia (NISHIDA et al., 2005). As primeiras considerações sobre domácias datam de 1887 por Goeldi, porém, durante séculos, as relações entre essas estruturas e a presença de artrópodes associados foram ignoradas (O’DOWD; WILLSON, 1989).

Em geral, domácias estão relacionadas com a defesa das plantas contra herbívoros e sua manutenção pelas plantas ao longo do processo evolutivo reforça a hipótese de existência do mutualismo entre plantas e artrópodes (BROUAT; MCKEY, 2000; MATOS et al., 2006). As domácias são principalmente habitadas por ácaros, predadores e fungívoros, que provêm benefícios às plantas (MATOS et al., 2006). Os ácaros se beneficiam do abrigo e do alimento proporcionado pelas domácias, enquanto as plantas utilizam a defesa destes animais contra herbívoros e patógenos (NORTON et al., 2001; IZZIO; VASCONCELOS, 2002; MATOS et al., 2006; EDWARDS et al., 2007).

Domácias são mais frequentes em angiospermas arbóreas, tropicais e subtropicais, e têm sido reportadas em 28\% das 290 famílias botânicas, como, por exemplo, em Melastomataceae, Rubiaceae, Nepenthaceae e Asclepiadaceae (WILKINSON, 1979; O’DOWD; WILLSON, 1989; MATOS et al., 2006). Brouwer e Clifford (1990) classificaram as domácias em diversos tipos como: cavidade, cavidade com domos, bolsas, bolsas com domos, tufos simples de tricomas e tufos complexos de tricomas. Além disto, podem variar em número e posição na face abaxial da lâmina foliar (O'DOWD; PEMBERTON, 1998, NISHIDA et al., 2005).

A família Melastomataceae compreende aproximadamente 4.000 espécies, distribuídas, principalmente, nas regiões tropicais, sendo especialmente abundante na flora brasileira (GOLDENBERG, 2000). Entre os inúmeros representantes brasileiros, o gênero Miconia é considerado um dos mais representativos e possui cerca de 1.000 espécies, não só no Brasil como em toda a América tropical e nos Andes (CLAUSING; RENNER, 2001). As domácias foram observadas em várias espécies da família (MICHELANGELI, 2010) como em Clidemia hammelii Almeda, Miconia pisinniflora Wurdack, Miconia pusilliflora Naudin e Miconia sellowiana Naudin (GOLDENBERG, 2000).

Ao analisar as domácias de Melastomataceae, Michelangeli (2010) identificou os gêneros que apresentam domácias associadas com formigas, chamados de mimercófitos. Em Miconia, foram identificadas quatro espécies mimercófitas, além de espécies que apresentam domácias associadas com ácaros, como é o caso de Miconia sellowiana (WHIFFIN, 1972; MICHELANGELI, 2010).

Miconia sellowiana é uma planta arbustivaarbórea, secundária inicial e heliófita facultativa. Seus representantes geralmente ocorrem em altitudes de 1.000 a $2.000 \mathrm{~m}$, raramente ao nível do mar. Os indivíduos, com hábito arbóreo e atingindo até $8 \mathrm{~m}$ de altura, podem ser encontrados em formações florestais secundárias, perenifólias ou semidecíduas, ou ainda em cerrado, e aqueles de hábito arbustivo, com menos de um metro de altura, em afloramentos rochosos (BOEGER et al., 2008; 2009). Diferenças significativas entre folhas de Miconia sellowiana provenientes de duas fitofisionomias, Floresta Ombrófila Mista (FOM) e Estepe Gramíneo-Lenhosa 
(EGL), foram observadas por Boeger et al. (2008; 2009). Folhas com características xeromórficas, como, maior valor médio para densidade estomática e de tricomas, maior espessura da cutícula da face adaxial, do parênquima esponjoso e espessura total da lâmina e menor valor médio para a área e massa seca foliar e área foliar específica, foram encontradas em indivíduos provenientes da EGL. Apesar das folhas desta espécie apresentarem diferentes adaptações morfoanatômicas às condições abióticas, as domácias estão presentes nas folhas de ambas as fitofisionomias (BOEGER et al., 2008; 2009).

Em geral, os estudos com domácias relacionam a condição ambiental com a comunidade de ácaros existentes nestas estruturas (WALTER; O'DOWD, 1995a; O'DOWD; WILLSON, 1989; NORTON et al., 2001; BRUNA et al., 2005; NISHIDA et al., 2005; O'CONNELL et al., 2010). Porém, são escassos os estudos que relacionam a morfologia das domácias com os fatores abióticos locais. Assim, esse estudo pretendeu avaliar a influência de fatores ambientais sobre a estrutura morfológica das domácias foliares de Miconia sellowiana provenientes de duas fitofisionomias distintas.

\section{Material e Métodos}

\section{Descrição das áreas de estudo}

A descrição completa das duas áreas de estudo, Floresta Ombrófila Mista (FOM) e Estepe GramíneoLenhosa (EGL), está disponível em Boeger et al. (2008; 2009).

a) Estepe Gramíneo-lenhosa (EGL): As plantas foram coletadas no "Buraco do Padre", na Fazenda "Nasce o dia", município de Ponta Grossa, PR, localizado no Segundo Planalto ou Planalto dos Campos Gerais (25'10'S e $\left.49^{\circ} 58^{\prime} \mathrm{W}\right)$. Miconia sellowiana ocorre na forma arbustiva nesse local.

b) Floresta Ombrófila Mista (FOM): As plantas foram coletadas na Fazenda Experimental do Canguirí, de propriedade da Universidade Federal do Paraná e localizada no município

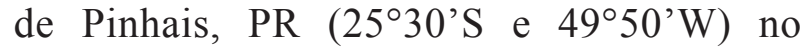
primeiro planalto. Miconia sellowiana ocorre na forma arbórea, nos estratos inferiores desta floresta.

\section{Metodologia}

As coletas foram efetuadas nos meses de abril e maio de 2003. Em cada fitofisionomia, ramos de seis indivíduos, que apresentavam a mesma fase fenológica e estavam sob a mesma intensidade de luz, foram coletados e, de cada ramo, 20 folhas foram selecionadas, totalizando 120 folhas. As folhas foram coletadas entre o terceiro e o sexto nós, no sentido ápice-base. Dezesseis folhas de cada indivíduo foram prensadas em jornal e secas em estufa, à temperatura de $65^{\circ} \mathrm{C}$, até atingirem peso constante, para a análise da morfologia foliar. A descrição completa da morfoanatomia das folhas de $M$. sellowiana pode ser encontrada em Boeger et al. (2008).

Para a análise anatômica, foram utilizadas amostras da região basal da folha, sendo duas folhas por indivíduo, para cada fitofisionomia. As amostras foram fixadas em FAA 70 (formaldeído, ácido acético, etanol $70 \%$, na proporção de 1:1:18 v/v) e, posteriormente, conservadas em álcool 70\% (JOHANSEN, 1940). Os segmentos foram incluídos em hidroxietilmetacrilato de acordo com as recomendações do fabricante (Leica $\left.{ }^{\circledR}\right)$. Posteriormente, seccionou-se o material em micrótomo rotatório, na espessura de $7 \mu \mathrm{m}$. As secções foram coradas com fucsina básica e azul de Astra, em solução aquosa (ALVES DE BRITO; ALQUINI, 1996) secas em estufa à $40^{\circ} \mathrm{C}$ e montadas entre lâmina e lamínula com Entellan ${ }^{\circledR}$. As fotomicrografias foram obtidas com câmera digital Canon Power Shot F50 acoplada em microscópio óptico Olympus BX51.

A análise da morfologia foliar baseou-se nas seguintes características: a área foliar $\left(\mathrm{cm}^{2}\right)$ estimada através da imagem digitalizada em scanner de mesa, acoplado ao computador, pelo software SigmaScanPro (versão 4.0, SPSS Inc., Chicago, IL, USA, 1995); e a área da domácia esquerda e da domácia direita, estimadas a partir das medidas de maior comprimento e maior largura (mm), obtidas com paquímetro digital. 
A área foi definida pela fórmula: $\mathrm{CD} \times \mathrm{LD} / 2$, onde $\mathrm{CD}$ $=$ comprimento mediano da domácia $\mathrm{e} \mathrm{LD}=$ maior largura da domácia.

A massa seca ( $\mathrm{g}$ ) foi estimada através de pesagem em balança analítica de precisão das folhas previamente desidratadas em estufa a $65^{\circ} \mathrm{C}$. As espessuras totais da lâmina foliar e da lâmina da domácia, em secções transversais, foram realizadas em microscópio óptico Olympus CBB, com auxílio de ocular micrometrada. As médias das variáveis quantitativas e respectivos desviospadrão foram calculadas e comparadas pelo teste " $\mathrm{t}$ " de student, no programa Statistica, versão 6.0 (StatSoft, Inc., Tulsa, OK, USA 1998).

\section{Resultados}

As folhas de Miconia sellowiana apresentam o padrão acródomo suprabasal de nervação, com três nervuras proeminentes (Figura 1). Na porção basal da face abaxial da lâmina, na junção das nervuras principais, ocorrem duas domácias, uma de cada lado da nervura central (Figura 1). Nas folhas de ambas as fitofisionomias, as domácias são do tipo cripta ou bolsa (Figura 1), com cavidade ampla e abertura estreita, côncavas na superfície abaxial, convexas na superfície adaxial e em secção transversal, apresentam formato de "u" invertido (Figura 2).

Em secção transversal, a lâmina foliar possui epiderme uniestratificada, com células retangulares e alongadas no sentido periclinal. As células epidérmicas, na face abaxial das plantas da FOM, são mais tabulares, diferenciando-se das células da face abaxial das plantas de EGL (Figuras 3A, 3B). O mesofilo das folhas de ambas as formações é organizado dorsiventralmente, sendo formado por parênquima paliçádico que varia de um a três estratos de células. Tanto as folhas da FOM com as folhas de EGL apresentam dois a três estratos de células do parênquima paliçádico e quatro a cinco estratos de células de parênquima esponjoso, sendo este último com espaços intercelulares pequenos e pouco evidentes (Figura 3A). Nas folhas de EGL, o parênquima esponjoso é mais compacto (Figura 3B).

FIGURA 2: Anatomia foliar, na região das domácias e da nervura central, de $M$. sellowiana de indivíduos provenientes de Floresta Ombrófila Mista (A) e Estepe GramíneoLenhosa (B). D: Domácia, NC: Parte da Nervura Central.

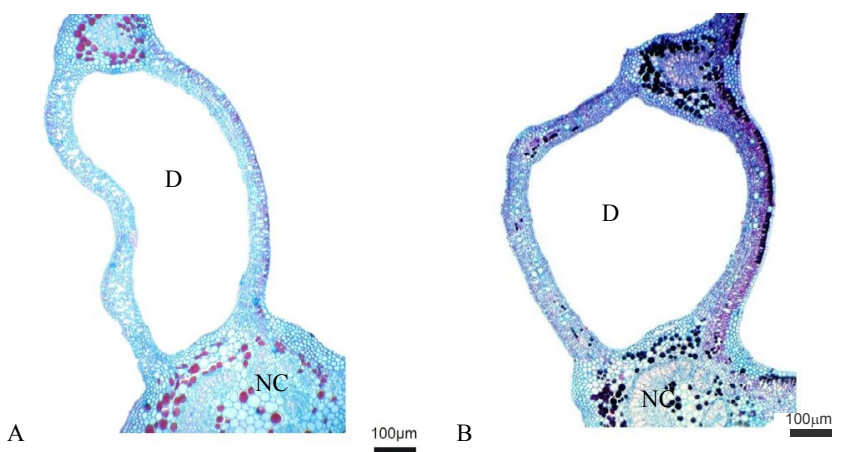

A nervura central, em secção transversal, apresenta epiderme unisseriada com células de formato isodiamétrico e paredes uniformemente espessadas (Figura 4A, 4B). Internamente à epiderme, ocorrem várias camadas de células de colênquima do tipo anelar (Figura 4A, 4B). Os feixes vasculares são anficrivais,

FIGURA 1: Folhas de Miconia sellowiana provenientes de duas fitofisionomias. A. Floresta Ombrófila Mista (FOM). B. Estepe-GramíneoLenhosa (EGL). C. Em detalhe, observa-se a presença de duas domácias na face abaxial da lâmina foliar, na junção das nervuras principais. A seta indica abertura superior da domácia do tipo bolsa.

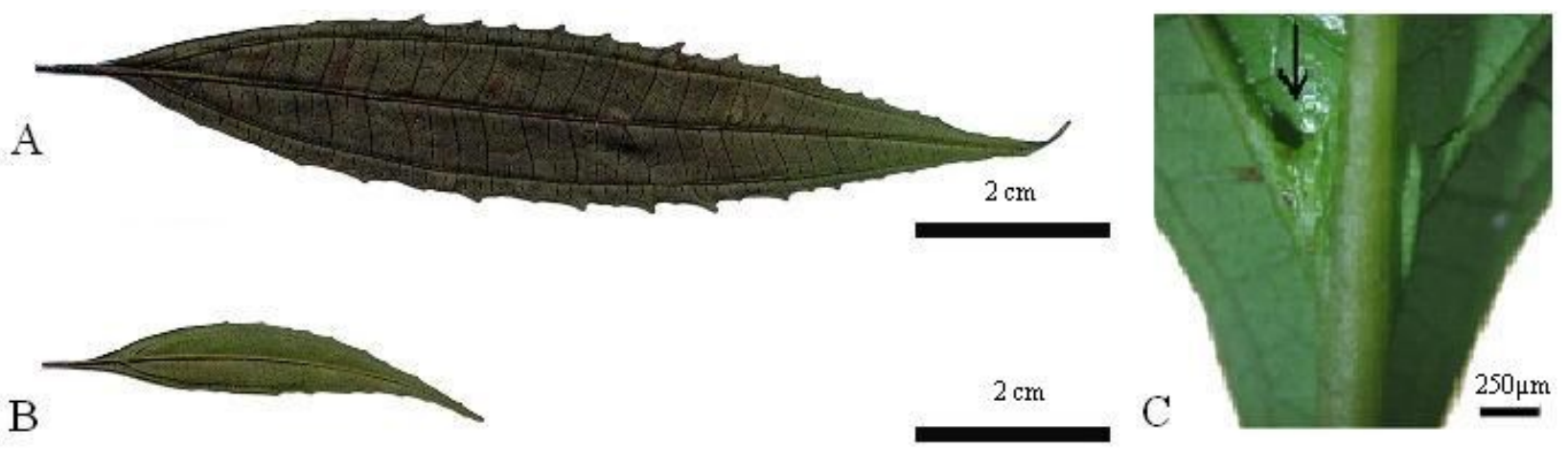


variando de dois a três, sendo um de maior porte, em forma de arco e voltado para a face abaxial. Os feixes menores estão próximos à face adaxial. Os feixes se encontram envoltos por células parenquimáticas, fibras isoladas e células com conteúdo denso e escuro.

FIGURA 3: Anatomia foliar de M. sellowiana de indivíduos provenientes de Floresta Ombrófila Mista (A) e Estepe Gramíneo-Lenhosa (B). Secção transversal evidenciando o mesofilo da lâmina foliar. AD: Face adaxial da epiderme; AB: Face abaxial da epiderme; EST: Estômato; PL: Parênquima lacunoso; PP: Parênquima paliçádico.

A

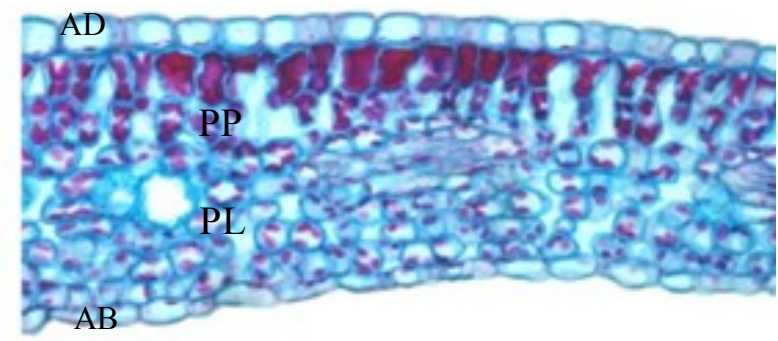

$50 \mu \mathrm{m}$

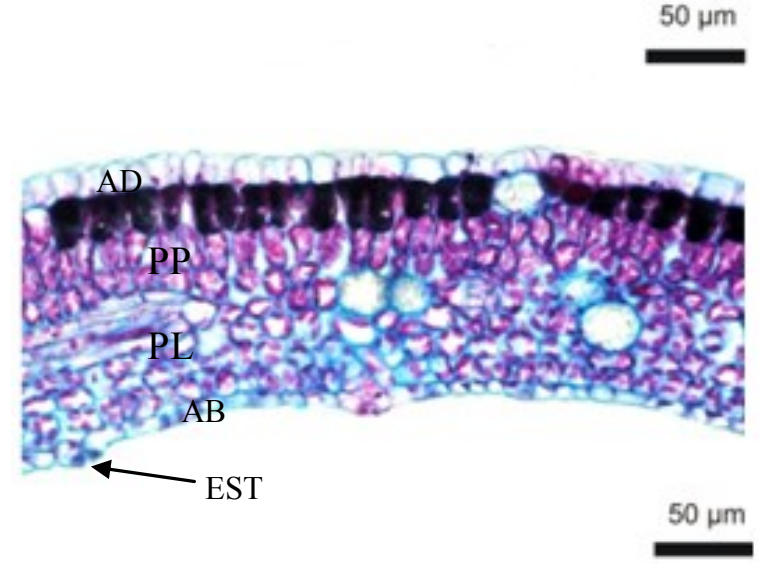

Em secção transversal, a domácia apresenta epiderme uniestratificada formada por células retangulares, com presença de uma fina cutícula nas duas faces. Não foram observados estômatos em ambas as faces. O mesofilo é homogêneo, sendo que as células clorofilianas apresentam formato irregular (Figura 5). $\mathrm{O}$ número de estratos celulares varia entre 8 a 12 nas domácias, nas duas fitofisionomias. Feixes vasculares de pequeno porte ocorrem imersos no mesofilo (Figura 5).
A análise quantitativa mostrou que as domácias variaram em tamanho entre as folhas das duas fitofisionomias (Tabela 1). A área das domácias apresentou uma relação inversa com a área foliar. A razão da área da domácia/área foliar foi maior nas folhas da EGL, em relação às folhas da FOM (Tabela 1). As folhas das EGL apresentaram domácias mais espessas do que as folhas da FOM, seguindo o mesmo padrão encontrado para as lâminas foliares (Figuras $3 \mathrm{~A}, 3 \mathrm{~B}, 5 \mathrm{~A}, 5 \mathrm{~B})$.

FIGURA 4: Anatomia foliar de M. sellowiana de indivíduos provenientes de Floresta Ombrófila Mista (A) e Estepe Gramíneo-Lenhosa (B). Secção transversal da folha na região da nervura central. CL: Colênquima; F: Floema; PF: Parênquima fundamental; X: Xilema.
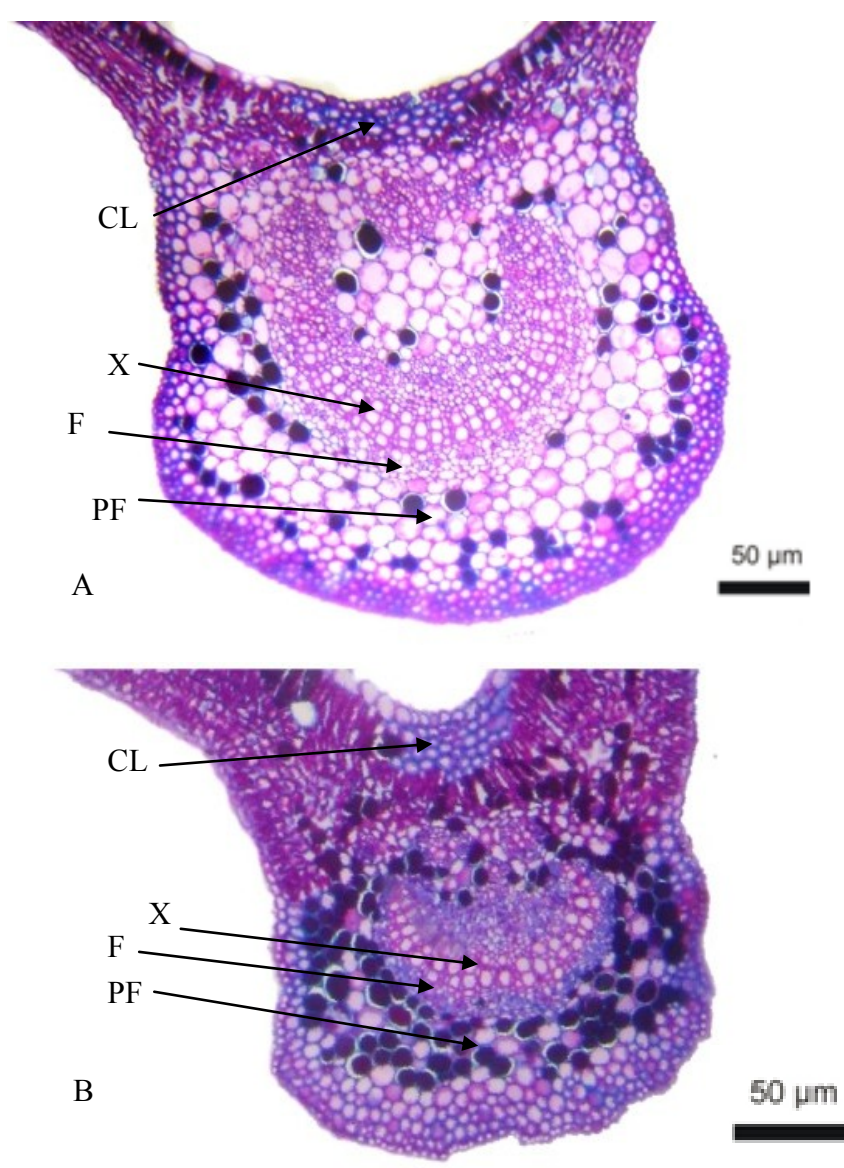
FIGURA 5: Anatomia foliar de M. sellowiana de indivíduos provenientes de Floresta Ombrófila Mista (A) e Estepe Gramíneo-Lenhosa (B). Secção transversal do mesofilo das domácias. EAB: Epiderme abaxial, EAD: Epiderme adaxial, MH: mesofilo homogêneo.

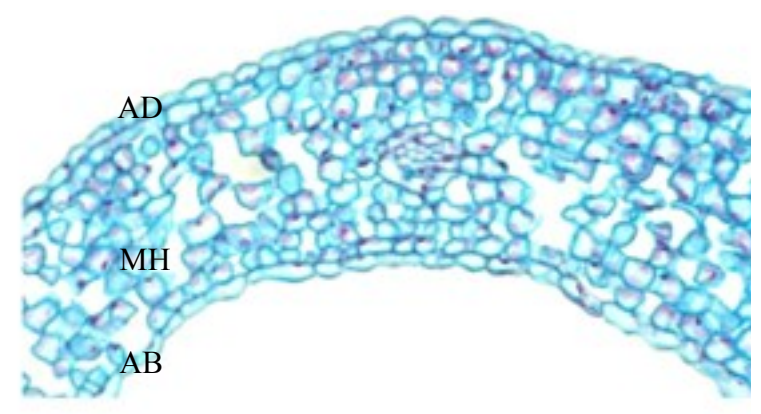

A

B

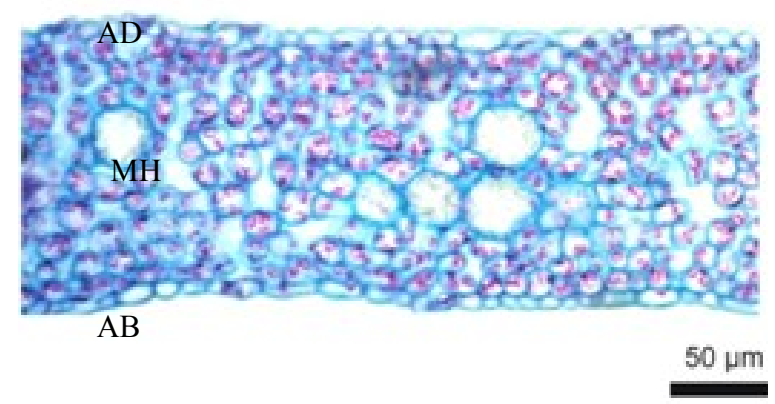

TABELA 1: Valores médios e respectivos desvios padrão (entre parênteses) da área da domácia esquerda $\left(\mathrm{AD}_{\mathrm{E}}\right)$, área da domácia direita $\left(\mathrm{AD}_{\mathrm{D}}\right)$, espessura da domácia direita $\left(\mathrm{ED}_{\mathrm{D}}\right)$, espessura da domácia esquerda $\left(\mathrm{ED}_{\mathrm{E}}\right)$, área foliar $(\mathrm{AF})$, massa seca (MS), espessura total da folha (EF) e razão da área média da domácia/área foliar $\left(\mathrm{A}_{\mathrm{D}} / \mathrm{A}_{\mathrm{F}}\right)$ das folhas de Miconia sellowiana nas diferentes fitofisionomias. Letras diferentes para a mesma variável (mesma linha) significam que os valores são estatisticamente diferentes ( $p<0,05),(n=16)$.

\begin{tabular}{lcc}
\hline $\begin{array}{c}\text { Características } \\
\text { Morfológicas }\end{array}$ & $\begin{array}{c}\text { Estepe Gramíneo- } \\
\text { Lenhosa }\end{array}$ & $\begin{array}{c}\text { Floresta } \\
\text { Ombrófila Mista }\end{array}$ \\
\hline $\mathrm{AD}_{\mathrm{D}}\left(\mathrm{mm}^{2}\right)$ & $0,91(0,56) \mathrm{a}$ & $0,61(0,35) \mathrm{b}$ \\
$\mathrm{AD}_{\mathrm{E}}\left(\mathrm{mm}^{2}\right)$ & $0,93(0,60) \mathrm{a}$ & $0,66(0,31) \mathrm{b}$ \\
$\mathrm{ED}_{\mathrm{D}}(\mu \mathrm{m})$ & $100,64(11,39) \mathrm{a}$ & $82,14(3,93) \mathrm{b}$ \\
$\mathrm{ED}_{\mathrm{E}}(\mu \mathrm{m})$ & $98,32(9,47) \mathrm{a}$ & $87,26(4,91) \mathrm{b}$ \\
$\mathrm{AF}\left(\mathrm{cm}^{2}\right)$ & $4,33(1,38) \mathrm{b}$ & $10,77(4,52) \mathrm{a}$ \\
$\mathrm{MS}(\mathrm{g})$ & $0,06(0,02) \mathrm{b}$ & $0,08(0,02) \mathrm{a}$ \\
$\mathrm{EF}(\mu \mathrm{m})$ & $161,63(4,25) \mathrm{a}$ & $76,63(2,06) \mathrm{b}$ \\
$\mathrm{A}_{\mathrm{D}} / \mathrm{A}_{\mathrm{F}}$ & $0,21(0,09) \mathrm{a}$ & $0,06(0,01) \mathrm{b}$ \\
\hline
\end{tabular}

\section{Discussão}

Em M. sellowiana, o número de domácias por folha é constante, ocorrendo apenas um par de domácias na base da folha, independente da fitofisionomia onde a espécie é encontrada, indicando que essa característica parece ser fixada geneticamente e não uma resposta à variação ambiental. Souza e Marquete (2000) também encontraram o mesmo padrão de domácias, em relação ao tipo e número, para o mesmo gênero, em Miconia tristis e Miconia doriana. O’Dowd e Pemberton (1998) analisaram as domácias em 24 espécies arbóreas, em diferentes famílias, em florestas da Korea, e encontraram um número variado de domácias, ocorrendo tanto em espécies com folhas simples como em folhas palmadas. Em Cinnamomum camphora (Lauraceae), as domácias ocorrem em diferentes posições na face adaxial, mas preferencialmente na região basal, na junção entre duas nervuras de maior porte (NISHIDA et al., 2005).

Apesar do mesmo número de domácias nas folhas das duas fitofisionomias, as domácias de EGL são maiores, apesar de apresentar menor área foliar. Essa aparente discrepância nos resultados pode ser parcialmente explicada pela influência das características ambientais sobre a comunidade de invertebrados hospedeiros (ZUNDEL et al., 2009; O'CONNELL et al., 2010). Domácias maiores podem hospedar ácaros maiores e ainda mais resistentes às condições ambientais já que, em EGL, parecem ser mais adversas, como altas temperaturas e menor umidade relativa do ar em determinada época do ano (BOEGER et al., 2008). As maiores espessuras das domácias encontradas nas folhas de EGL também corroboram com essa hipótese. Segundo O'Connell et al. (2010), as variações nas condições ambientais que afetam a estrutura da vegetação podem alterar os mecanismos responsáveis pela produção de domácias nas plantas, influenciando na quantidade de biomassa investida em novas folhas ou domácias, por exemplo. Consequentemente, as condições microclimáticas da lâmina foliar podem gerar um hábitat heterogêneo e estressante para muitos invertebrados. Uma maior umidade relativa na lâmina foliar, proveniente da atividade fotossintética, parece ser mais benéfica para a associação com hospedeiros mais sensíveis à baixa umidade, selecionando estes organismos numa 
estreita relação de mutualismo (DJIETO-LORDON; DEJEAN, 1999; BROUAT; MCKEY, 2000; BRUNA et al., 2005; EDWARDS et al., 2007; ZUNDEL et al., 2009). Em contrapartida, as condições climáticas como temperatura e umidade relativa do ar podem influenciar na comunidade de ácaros que está presente nas folhas, no que se refere ao tamanho e espécies de ácaros que ocorrem nas domácias (WALTER; O'DOWD, 1995a; 1995b; O’DOWD; PEMBERTON, 1998; O'CONNELL et al., 2010).

As domácias são encontradas predominantemente em espécies arbóreas de clima tropical ou subtropical úmido e ainda não foram relatadas para espécies vegetais de ambientes permanentemente secos (WILKINSON, 1979). Provavelmente, isso se deve ao fato da ocorrência de domácias estar estritamente relacionada com a comunidade de artrópodes hospedeiros, pois em florestas tropicais com estações mais secas, a sobrevivência dos artrópodes hospedeiros é negativamente influenciada pela baixa umidade relativa do ar (ZUNDEL et al., 2009, O’CONNELL et al., 2010).

Os ambientes florestais ombrófilos, como a FOM, se caracterizam pela presença de vários estratos, solo com maior capacidade de retenção de água, pluviosidade elevada e alta umidade relativa do ar, propiciando maior disponibilidade de água para as plantas. Indivíduos arbóreos que compõem o sub-bosque apresentam folhas maiores e, consequentemente, maior massa seca e menor espessura da lâmina. Estas características são geralmente associadas ao investimento da planta no processo de captura de luz, pois quanto maior a superfície da lâmina, mais eficaz é esse processo, principalmente em ambientes com alta umidade relativa do ar (MARQUES et al., 1999; 2000; NAVAS; GARNIER, 2002; SULTAN, 2003; BOEGER et al., 2008),

Já a EGL caracteriza-se por apresentar espécies com indivíduos de pequeno porte, que recebem intensa radiação solar durante o dia. Apesar da alta pluviosidade, a condição do solo raso com baixa capacidade de retenção de água, acarreta um estresse hídrico às plantas, resultando no aprimoramento dos mecanismos que minimizam as perdas de água, como folhas pequenas e espessas (GROOM; LAMONT, 1995; NODA et al., 2004, BOEGER et al., 2008; 2009). Folhas menores apresentam menor superfície de contato com o ar e, por conseguinte, menor área de trocas gasosas entre a folha e a atmosfera, diminuindo a perda de água pela transpiração (TAKENAKA et al., 2001; FALSTER; WESTOBY, 2003; GÁLVEZ; PEARCY, 2003).

As domácias estudadas apresentaram uma estrutura anatômica mais simples do que a lâmina foliar na qual estão localizadas. Hamilton (1896), ao estudar as domácias de algumas espécies vegetais australianas, sugere que a principal diferença entre as domácias e a lâmina foliar está na ocorrência do parênquima esponjoso mais compacto nas domácias. As domácias de $M$. sellowiana estudadas, provenientes tanto de FOM quanto EGL, apresentam na face abaxial um mesofilo homogêneo, com células irregulares. A não diferenciação entre parênquima paliçádico e esponjoso na domácias, juntamente com a ausência de estômatos, tanto na face abaxial quanto adaxial, sugerem que a capacidade fotossintética das domácias é menor que a da lâmina foliar (LEROY et al., 2010). As diferenças anatômicas entre domácias e lâmina foliar parece ser resultado da especialização da domácia em servir de local de abrigo e alimentação para os artrópodes (LEROY et al., 2008). Este padrão diferenciado também foi identificado para Hirtella physophora (Chrysobalanaceae) e outras espécies de Melastomataceae, como Maieta guianensis Aublet e Tococa guianensis Aublet (LEROY et al., 2010).

No entanto, o entendimento da formação e ocorrência de domácias em espécies de ampla distribuição geográfica ainda necessita de ampla investigação. Estudos sobre a ontogenia das domácias, assim como a identificação da comunidade de ácaros em cada fitofisionomia, parecem ser passos decisivos para a melhor compreensão sobre as domácias e a sua importância nesta relação complexa entre plantas e artrópodes, como o mutualismo.

\section{Agradecimentos}

Ao Conselho Nacional de Desenvolvimento Científico e Tecnológico ( $\mathrm{CNPq}$ ), pela bolsa de Produtividade em Pesquisa concedida aos Prof ${ }^{a}$ Maria Regina Torres Boeger e Renato Goldenberg e à Sikandra- 
Lis Fonseca Paulinelli Garcia da Silveira pelo auxílio com as fotomicrografias.

\section{Referências}

ALVES DE BRITO, C. J. F.; ALQUINI, Y. A new method for staining botanical material embedded in glycol methacrylate. Arquivos de Biologia e Tecnologia, Curitiba, v. 39, p. 949-951, 1996.

BOEGER, M. R. T.; BIU, C.; GOLDENBERG, R. Arquitetura foliar comparativa de Miconia sellowiana (DC.) Naudin (Melastomataceae) em diferentes fitofisionomias no estado do Paraná. Acta Botanica Brasilica (Impresso), Feira de Santana, v. 23, p. 657-665, 2009.

BOEGER, M. R. T.; GLUZEZAK, R. M.; PIL, M. W.; GOLDENBERG, R.; MEDRI, M. Variabilidade morfológica foliar de Miconia sellowiana Naudin (Melastomataceae) em diferentes fitofisionomias no Estado do Paraná. Revista Brasileira de Botânica, São Paulo, v. 31, p. 443-452, 2008.

BROUAT, C.; MCKEY, D. Origin of caulinary ant domatia and timing of their onset in plant ontogeny: evolution of a key trait in horizontally transmitted ant-plant symbioses. Biological Journal of the Linnean Society, London, v. 71, p. 801-819, 2000.

BROUWER, Y. M.; CLIFFORD, H. T. An annotated list of domatia-bearing species. Notes from the Jodrell Laboratory, Royal Botanical Gardens, Kew, Richmond, v. 12, p. 1-33, 1990.

BRUNA, E. M.; VASCONCELOS, H. L.; HEREDIA, S. The effect of habitat fragmentation on communities of mutualists: a test with Amazonian ants and their host plants. Biological Conservation, Orlando, v. 124, p. 209-216, 2005.

CLAUSING, G.; RENNER, S. S. Molecular phylogenetics of Melastomataceae and Memecylaceae: implications for character evolution. American Journal of Botany, Saint Louis, v. 88, p. 486-498, 2001.

DJIETO-LORDON, C.; DEJEAN, A. Innate attraction supplants experience during host plant selection in an obligate plant-ant. Behavioural Processes, Amsterdam, v. 46, p. 181-187, 1999.

EDWARDS, D. P.; ARAUCO, R.; HASSALL, M.; SUTHERLAND, W. J.; CHAMBERLAINS, K.; WADHAM, L. J.; YU, D. W. Protection in an ant-plant mutualism: an adaptation or sensory trap? Animal Behaviour, Amsterdam, v. 74, p. 577-585, 2007.

FALSTER, D. S.; WESTOBY, M. Leaf size and angle vary widely across species: what consequences for light interception? New Phytologist, Oak Ridge, v. 158, n. 3, p. 509-525, 2003.

GALVEZ, D.; PEARCY, R. W. Petiole twisting in the crows of Psychotria limonensis: implications for light interception and daily carbon gain. Oecologia, Heidelberg, v. 135, n. 1, p. 22-29, 2003.

GOLDENBERG, R. O Gênero Miconia Ruiz et Pavon (Melastomataceae): I. Listagens Analíticas; II. Revisão Taxonômica da Seção Hypoxanthus (Rich. ex DC.) Hook.f. 2000. 259 f. Tese (Doutorado em Biologia Vegetal) - Universidade Estadual de Campinas, Campinas, 2000.

GROOM, P. K.; LAMONT, B. B. Leaf morphology and life form influences water relations of Hakea species on different soil substrates within southwestern Australia. Acta Oecologica, Paris, v. 16, p. 609-620, 1995.
HAMILTON, A. G. On domatia in certain Australian and other plants. Proceedings of Linnean Society of New South Wales, Sydney, v. 21, p. 758-792, 1896.

IZZO, T. J.; VASCONCELOS, H. L. Cheating the cheater: domatia loss minimizes the effects of ant castration in an Amazonian antplant. Oecologia, Heidelberg, v. 133, p. 200-205, 2002.

JOHANSEN, D. A. Plant microtechnique. New York: McGraw Hill Book, 1940. 523 p.

LEROY, C.; JAUNEAU, A.; QUILICHINI, A.; DEJEAN, A.; ORIVEL, J. Comparison between the anatomical and morphological structure of leaf blades and foliar domatia in the ant-plant Hirtella physophora (Chrysobalanaceae). Annals of Botany, Exeter, v. 101, p. 501-507, 2008.

LEROY, C.; JAUNEAU, A.; QUILICHINI, A.; DEJEAN, A.; ORIVEL, J. Comparative structure and ontogeny of the foliar domatia in three neotropical myrmecophytes. American Journal of Botany, Saint Louis, v. 97, n. 4, p. 00-00, 2010.

MARQUES, A. R.; GARCIA, Q. S.; FERNANDES, G. W. Effects of sun and shade on leaf structure and sclerophylly of Sebastiania myrtilloides (Euphorbiaceae) from Serra do Cipó, Minas Gerais, Brazil. Boletim Botânica da Universidade São Paulo, São Paulo, v. 18, p. 21-27, 1999.

MARQUES, A. R.; GARCIA, Q. S.; REZENDE, J. L. P.; FERNANDES, G. W. Variations in leaf characteristics of two species of Miconia of the Brazilian cerrado under different light intensities. Tropical Ecology, Varanasi, v. 40, n. 1, p. 47-60, 2000. MATOS, C. H. C.; PALLINI, A.; BELLINI, L. L.; FREITAS, R. C. P. Domácias e seu papel na defesa das plantas. Ciência Rural, Santa Maria, v. 36, n. 3, p. 1021-1026, 2006.

MICHELANGELI, F. A. Neotropical Myrmecophilous Melastomataceae: an annotated list and key. Proceedings of the California Academy of Sciences (Series 4), San Francisco, v. 61, n. 9 , p. 409-449, 2010.

NAVAS, M. L.; GARNIER, E. Plasticity of whole plant and leaf traits in Rubia peregrina in response to light, nutrient and water availability. Acta Oecologica, Paris, v. 23, p. 375-383, 2002.

NISHIDA, S.; NAIKI, A.; NISHIDA, T. Morphological variation in leaf domatia enables coexistence of antagonistic mites in Cinnamomum camphora. Canadian Journal of Botany, Ottawa, v. 83, p. 1-9, 2005.

NODA, H.; MURAOKA, H.; WASHITANI, I. Morphological and physiological acclimation responses to contrasting light and water regimes in Primula sieboldii. Ecological Research, Tokyo, v. 19, p. 331-340, 2004.

NORTON, A. P; ENGLISH-LOEB, G.; BELDEN, E. Host plant manipulation of natural enimies: leaf domatia protect beneficial mites from insect predators. Oecologia, Heidelberg, v. 126, p. 535542,2001

O'CONNELL, D. M; LEE, W. G.; MONSK, A.; DICKINSON, K. J. M. Does microhabitat structure affect foliar mite assemblages? Ecological Entomology, London, v. 35, p. 317-328, 2010.

O'DOWD, D. J.; PEMBERTON, R. W. Leaf domatia and foliar mite abundance in broadleaf deciduous forest of north Asia. American Journal of Botany, Saint Louis, v. 85, p. 70-78, 1998.

O’DOWD, D. J.; WILLSON, M. F. Leaf domatia and mites on Australasian plants: ecological and evolutionary implications. 
Biological Journal of the Linnean Society, London, v. 37, p. 191236, 1989.

SOUZA, R. S. O. C.; MARQUETE, O. Miconia tristis Spring e Miconia doriana Cogn. (Melastomataceae): anatomia do eixo vegetativo e folhas. Rodriguésia, Rio de Janeiro, v. 51, n. 78/79, p. 133-142. 2000

SULTAN, S. E. Phenothypic plasticity in plants: a case study in ecological development. Evolution and Development, McLean, v. 5, p. 25-33, 2003.

TAKENAKA, A.; TAKAHASHI, K.; KOHYAMA, T. Optimal leaf display and biomass partitioning for efficient light capture in an understorey palm, Licuala arbuscula. Functional Ecology, London, v. 15, p. 660-668, 2001.

WALTER, D. E.; O'DOWD, D. J. Life on the forest phylloplane: hairs, little houses, and myriad mites. In: LOWMAN, M. E.; NADKARNI, N. (Eds). Forest Canopies. New York: Academic Press, New York. 1995a. p. 325-351
WALTER, D. E.; O'DOWD, D. J. Beneath biodiversity: factors influencing the diversity and abundance of canopy mites. Selbyana, Sarasota, v. 16, p. 12-20, 1995 b.

WILKINSON, H. P. The plant surface (mainly leaf), part IV domatia. In: METCALFE, C. R.; CHALK, L. (Eds). Anatomy of the dicotyledons. v. 1.2 ed. Oxford: Clarendon Press,1979. p. $132-$ 140 .

WHIFFIN, T. Observations on some upper amazonian formicarial melastomaceae. SIDA, Saint Louis, v. 5, n. 1, p. 33-41. 1972.

ZUNDEL, C.; NAGEL, P.; HANNA, R.; KORNER, F.; SCHEIDEGGER, U. Environment and host-plant genotype effects on the seasonal dynamics of a predatory mite on cassava in subhumid tropical Africa. Agricultural and Forest Entomology, London, v. 11, p. 321-331, 2009. 